\title{
The impact of multiple chronic diseases on hospitalizations for ambulatory care sensitive conditions
}

\author{
Inês Dantas ${ }^{1 *}$, Rui Santana ${ }^{2,3}$, João Sarmento ${ }^{1}$ and Pedro Aguiar ${ }^{3,4}$
}

\begin{abstract}
Background: The high financial burden of avoidable hospitalizations has led to an increase of the study of hospitalizations for ambulatory care sensitive conditions (ACSC). There is limited information on the impact of secondary diagnoses on these hospitalizations, although patients' social and demographic characteristics, as well as the coexistence of multiple diseases are often identified in the literature as risk factors for avoidable hospitalizations. This study explores the impact of chronic conditions on the likelihood of hospitalizations for ACSC.

Methods: Data were extracted from the Portuguese hospital discharge database. Avoidable hospitalizations were identified according to the Canadian Institute for Healthcare Information, and chronic conditions were identified according to criteria set by the Agency for Healthcare Research and Quality. A retrospective study analysing all patients hospitalized for an ACSC and all patients hospitalized for non-ACSC was made, using multiple logistic regression models to identify the impact of chronic conditions on the risk of admission.

Results: The risk of an avoidable hospitalization increases by a factor of 1.35 (95 \% Cl [1.34;1.35]) for each additional chronic condition, and 1.55 (95\% Cl [1.55;1.56]) for each additional body system affected. The respiratory and circulatory systems have the most impact on the risk of ACSC, increasing the risk by 8.72 (95\% Cl [8.58;8.86]) and 3.01 (95\% Cl [2.95;3.06]), respectively.
\end{abstract}

Conclusions: The number of chronic conditions and the body systems affected increase the risk of hospital admissions for ACSC.

Keywords: Avoidable hospitalizations, Ambulatory care sensitive conditions, Chronic conditions

\section{Background}

Ambulatory care sensitive conditions (ACSC) are conditions for which earlier and more effective ambulatory care can avoid or decrease the rate of hospitalizations [1]. The potential to reduce avoidable hospitalizations associated with these conditions has attracted the interest of healthcare managers, researchers and policy makers in several countries including the United States [2], Canada [3], Australia [4], United Kingdom [5], Spain [6], and Portugal [7].

\footnotetext{
*Correspondence: isadantas@gmail.com

${ }^{1}$ National School of Public Health (ENSP), Universidade NOVA de Lisboa, Av. Padre Cruz, 1600-560 Lisbon, Portugal

Full list of author information is available at the end of the article
}

ACSC are frequently referred to in literature as an indicator of access to care, with the goal of raising awareness of the importance of integrating care as a priority in health policies. The study of ACSC is even more important in the face of current socio-demographic and epidemiological trends, such as aging of the population and living longer with chronic conditions [8], which pose challenges to the needs and expectations of healthcare consumers.

In the United Sates, $65 \%$ of people aged 65 years and older have at least two chronic conditions [9] and $32 \%$ of the hospitalizations are considered to be preventable [10]. Moreover, the likelihood of an ACSC hospitalization for patients with more than one chronic condition is greater than $25 \%$ [11]. This can be partly 
explained by the under treatment of an unrelated chronic condition [12].

Wolff et al. (2002) studied the prevalence and complications associated with multiple chronic conditions in the Medicare beneficiaries in the United States, observing that the odds of being hospitalized due to an ACSC is 7.5 and 98.5 times greater for patients with at least one and at least four chronic conditions, respectively, when compared to patients without chronic conditions [9].

The relationship between ACSC and the presence of chronic illness is complex in nature, as patients often have multiple chronic conditions. An examination of principal diagnoses and specific combinations of nonprincipal diagnoses reported in earlier studies show varying levels of risk for an ACSC hospitalization. For example, patients with neurological disorders are 2.6 times more likely to be hospitalized due to an ACSC than patients without neurological disorders [13]; type II diabetes patients, also have a higher probability of an ACSC hospitalization and $96 \%$ have a second chronic condition [14]; and heart failure patients have a $95 \%$ probability of a non-cardiac comorbidity that complicates the original condition [10].

ACSC hospitalizations are proving valuable in measuring access to care and their use as a measure is being adopted by healthcare systems and providers. Combined with the lack of knowledge of the impact of non-principal diagnoses in such hospitalizations, there is a clear need to study how the number of chronic conditions and the body systems they belong to play into ACSC hospitalizations.

\section{Methods}

\section{Data collection and sampling}

We obtained the data used in this study from the Central Administration of the Health System database, which includes patient-level data for all inpatient admissions in mainland Portuguese public hospitals. We considered the available data from 2008 to 2012, as it was the most up to date data set covering five continuous years of data at the start of this study.

The database includes several variables from inpatient admission records including: patient identifier (anonymized), gender, date of birth, principal and secondary diagnoses (using ICD-9-CM), Major Disease Categories of Diagnosis Related Groups (DRG) classification (AP-DRG v27), DRG type (surgical or medical), admission type (emergency or elective), and length of stay, amongst others.

From the original database we excluded the following records:

- Death before discharge;

- Hospitalization length of stay of 0 or more than 39 days (patients with the selected length of stay cover $99 \%$ of the ACSC population);
- Patients less than 36 years old or more than 75 years old (patients with the selected age cover $80 \%$ of the ACSC population).

The final sample included 1,975,542 hospitalizations, accounting for $22 \%$ of the episodes in the original database.

\section{Identification of ACSC and chronic conditions}

We evaluated each hospitalization to identify whether the principal diagnosis was an ambulatory care sensitive condition, using the Canadian Institute for Healthcare Information's methodology [15]. This method identifies ACSC through ICD-9-CM codes, and groups ACSC into seven categories: grand mal status and other epileptic convulsions, chronic obstructive pulmonary diseases (COPD), asthma, diabetes, heart failure and pulmonary edema (HFPE), hypertension (HTN), and angina.

To identify chronic diseases and the respective body systems, we used the Chronic Condition Indicator methodology, developed as part of the Agency for Healthcare Research and Quality's Healthcare Cost and Utilization Project [16]. We flagged each diagnosis as a chronic or non-chronic condition, and we identified the body system the chronic condition belongs to - from a predefined list of 18 body systems. Body systems analysis enabled us to study the presence of chronic conditions in additional body systems, identifying only conditions that are distinct from each other. This resulted in the following variables:

- Chronic conditions, which identifies whether the diagnosis is a chronic condition;

- Body systems, which identifies the body system to which the chronic condition relates to;

- Number of chronic conditions for a given patient;

- Number of body systems in which the patient has chronic conditions.

\section{Statistical analysis}

We characterized the sample using descriptive statistics taking into consideration gender, age, admission type, discharge status, length of stay, and DRG type. The study population was divided into two groups: hospitalizations for an ACSC and non-ACSC hospitalizations. We validated the differences between the samples using the Student's $t$ test and the chi-square test.

We used multiple logistic regressions to evaluate the impact of the non-principal diagnoses in ACSC hospitalizations, adjusted for age and gender. We considered a $95 \%$ confidence interval, and tests with a $p$-value $<0.05$ were considered to be statistically significant. 


\section{Results}

\section{Study population}

The sample had a slightly higher proportion of women (51.5\%) and a concentration in older age groups. Emergency admissions accounted for $50.7 \%$ of the hospitalizations and $95.6 \%$ of the patients were discharged to home. The sample was almost evenly distributed by DRG type, with $49.9 \%$ medical and $50.1 \%$ surgical hospitalizations. The full characterization of the study population is in Table 1.

Of all hospitalizations, $4.5 \%$ were attributed to ambulatory care sensitive conditions. Among these hospitalizations, $28.5 \%$ were attributed to heart failure and pulmonary edema and $25.8 \%$ were attributed to COPD. In the 71 to 75 year old age group, the hospitalization rate for ACSC was $8.0 \%$, almost double the rate for the overall sample.

When comparing ACSC hospitalizations with nonACSC hospitalizations, we observed a higher frequency of males $(58.3 \%, p<0.001)$ and older patients $(p<0.001)$.
For ACSC hospitalizations the admission type is emergency in $87.2 \%$ of cases and the DRG is medical in most cases $(97.6 \%)$. The average length of stay increases from 6.50 days to $7.71(p=0.021)$ and the DRG weight rises from 0.9853 to $0.9858(p<0.001)$.

\section{Chronic conditions in the population}

Just over half (51.7\%) of all patients had at least two chronic conditions and $20.3 \%$ had at least four chronic conditions. These rates increased to $88.0 \%$ and $50.4 \%$ respectively for the ACSC hospitalizations group. The average number of chronic conditions in the ACSC group was 3.93, twice the average of the non-ACSC group $(p=0.008)$. Moreover, the ACSC group chronic conditions affected an average of 2.5 body systems, compared to 1.49 body systems in the non-ACSC group $(p=0.004)$. These results are in Table 2.

To better understand how chronic conditions relate to each specific ACSC, we further studied four subpopulations, corresponding to the hospitalizations in

Table 1 Descriptive characteristics comparison of the study's population and sub-groups

\begin{tabular}{|c|c|c|c|c|c|c|c|}
\hline \multirow{2}{*}{ Total cases } & \multicolumn{2}{|c|}{ All hospitalizations } & \multicolumn{2}{|c|}{ Non-ACSC Hospitalizations } & \multicolumn{2}{|c|}{ Hospitalizations for ACSC } & \multirow[t]{2}{*}{$p$} \\
\hline & 1975542 & & 1886302 & & 89240 & & \\
\hline Gender & & & & & & & $<0.001$ \\
\hline Male & 958003 & $(48.5 \%)$ & 906014 & $(48 \%)$ & 51989 & (58.3 \%) & \\
\hline Age group & & & & & & & $<0.001$ \\
\hline 36 to 40 years & 210685 & $(10.7 \%)$ & 207653 & (11\%) & 3032 & $(3.4 \%)$ & \\
\hline 41 to 45 years & 184038 & $(9.3 \%)$ & 180100 & $(9.5 \%)$ & 3938 & $(4.4 \%)$ & \\
\hline 46 to 50 years & 205990 & $(10.4 \%)$ & 200420 & (10.6\%) & 5570 & $(6.2 \%)$ & \\
\hline 51 to 55 years & 227045 & $(11.5 \%)$ & 219142 & $(11.6 \%)$ & 7903 & $(8.9 \%)$ & \\
\hline 56 to 60 years & 250149 & $(12.7 \%)$ & 239814 & $(12.7 \%)$ & 10335 & $(11.6 \%)$ & \\
\hline 61 to 65 years & 271717 & $(13.8 \%)$ & 258122 & (13.7\%) & 13595 & $(15.2 \%)$ & \\
\hline 66 to 70 years & 290768 & $(14.7 \%)$ & 272663 & (14.5 \%) & 18105 & $(20.3 \%)$ & \\
\hline 71 to 75 years & 335150 & $(17 \%)$ & 308388 & (16.3\%) & 26762 & $(30 \%)$ & \\
\hline Admission type & & & & & & & $<0.001$ \\
\hline Elective & 892426 & (45.2\%) & 881037 & (46.7 \%) & 11389 & $(12.8 \%)$ & \\
\hline Emergency & 1001108 & $(50.7 \%)$ & 923298 & (48.9 \%) & 77810 & (87.2 \%) & \\
\hline Others & 82008 & $(4.2 \%)$ & 81967 & $(4.3 \%)$ & 41 & (0 \%) & \\
\hline Average length of stay (days) & 6.55 & & 6.50 & & 7.71 & & 0.021 \\
\hline Type of DRG & & & & & & & $<0.001$ \\
\hline Surgical & 989623 & $(50.1 \%)$ & 987514 & $(52.4 \%)$ & 2109 & $(2.4 \%)$ & \\
\hline Medical & 985073 & $(49.9 \%)$ & 897943 & $(47.6 \%)$ & 87130 & (97.6 \%) & \\
\hline Other & 846 & (0 \%) & 845 & $(0 \%)$ & 1 & (0 \%) & \\
\hline Average of DRG weight & 0.9853 & & 0.9853 & & 0.9858 & & 0.003 \\
\hline Discharge status & & & & & & & $<0.001$ \\
\hline Home & 1887677 & (95.6 \%) & 1802660 & (95.6 \%) & 85017 & $(95.3 \%)$ & \\
\hline Another hospital & 61246 & (3.1\%) & 58141 & (3.1\%) & 3105 & $(3.5 \%)$ & \\
\hline Others & 26619 & $(1.3 \%)$ & 25501 & (1.4\%) & 1118 & (1.3\%) & \\
\hline
\end{tabular}


Table 2 Number of chronic conditions and body systems affected in the study's population and sub-groups

\begin{tabular}{llll}
\hline & All hospitalizations & Non-ACSC hospitalizations & Hospitalizations for ACSC \\
\hline Number of hospitalizations & 1975542 & 1886302 & 89240 \\
Average number of chronic conditions & 2.07 & 1.98 & 3.93 \\
Number of chronic conditions (\% of column) & & & 100.0 \\
At least 1 & 76.3 & 75.2 & 88.0 \\
At least 2 & 51.7 & 50.0 & 69.7 \\
At least 3 & 33.4 & 31.7 & 50.4 \\
At least 4 & 20.3 & 18.9 & 2.50 \\
Average number of body systems & 1.53 & 1.49 & 100.0 \\
Number of additional body systems (\% of column) & & & 78.4 \\
At least 1 & 76.3 & 75.2 & 43.7 \\
At least 2 & 44.9 & 43.3 & 18.6 \\
At least 3 & 21.0 & 19.9 & 0.004 \\
At least 4 & 7.7 & 7.2 & \\
\hline
\end{tabular}

which the principal diagnosis belonged to one of the four most frequent body systems in ACSC hospitalizations: endocrine, nutritional, metabolic diseases, and immunity disorders; diseases of the nervous system and sense organs; diseases of the circulatory system; and diseases of the respiratory system. In these sub-populations, more than $54.0 \%$ of hospitalizations have additional chronic conditions. This value rose to $89.4 \%$ when the principal diagnosis is a disease of the circulatory system, reflecting the increased disease accumulation in these cases. More than $8.7 \%$ of this population has chronic conditions in at least four different body systems. Regardless of the chronic condition that is responsible for the hospitalization, most patients accumulate chronic conditions in the following body systems: endocrine, nutritional, metabolic diseases, and immunity disorders, diseases of the circulatory system, and diseases of the respiratory system (Table 3).

Table 3 Chronic conditions and body systems in the admissions for the most common ACSC

\begin{tabular}{|c|c|c|c|c|c|}
\hline & \multicolumn{5}{|c|}{ Hospitalizations with a primary diagnosis of } \\
\hline & $\begin{array}{l}\text { Endocrine, nutritional, and metabolic } \\
\text { diseases and immunity disorders }\end{array}$ & $\begin{array}{l}\text { Diseases of the nervous } \\
\text { system and sense organs }\end{array}$ & $\begin{array}{l}\text { Diseases of the } \\
\text { circulatory system }\end{array}$ & $\begin{array}{l}\text { Diseases of the } \\
\text { respiratory system }\end{array}$ & $p$ \\
\hline Number of hospitalizations & 61108 & 54575 & 263642 & 36180 & \\
\hline $\begin{array}{l}\text { Average number of chronic } \\
\text { conditions }\end{array}$ & 3.12 & 2.23 & 3.91 & 3.47 & $<0.001$ \\
\hline \multicolumn{6}{|l|}{$\begin{array}{l}\text { Number of chronic conditions } \\
\text { (\% of column) }\end{array}$} \\
\hline At least 2 & 74.2 & 54.0 & 89.4 & 79.9 & \\
\hline At least 3 & 51.3 & 32.0 & 72.0 & 60.5 & \\
\hline At least 4 & 33.5 & 17.8 & 51.6 & 41.8 & \\
\hline Average number of body systems & 2.24 & 1.84 & 2.19 & 2.55 & $<0.001$ \\
\hline \multicolumn{6}{|l|}{$\begin{array}{l}\text { Additional body systems } \\
\text { (\% of column) }\end{array}$} \\
\hline At least 1 & 68.1 & 47.9 & 72.4 & 73.9 & \\
\hline At least 2 & 34.8 & 24.8 & 31.7 & 47.2 & \\
\hline At least 3 & 14.6 & 8.7 & 10.6 & 22.0 & \\
\hline \multicolumn{6}{|l|}{ Most common body system } \\
\hline Rank 1 & Circulatory (45.0 \%) & Circulatory (25.9\%) & Endocrine (54.3 \%) & Circulatory (45.7 \%) & \\
\hline Rank 2 & Nervous (17.3\%) & Endocrine (21.9 \%) & Mental (17.1\%) & Endocrine (33.7 \%) & \\
\hline Rank 3 & Mental (12.7 \%) & Mental (14.3\%) & Nervous (9.3\%) & Mental (21.3 \%) & \\
\hline
\end{tabular}


Impact of chronic conditions in ACSC hospitalizations

Being a male and in a higher age group increased the risk of an ACSC hospitalization in every model.

For each chronic condition a patient had, the risk of an ACSC hospitalization increased 1.35 times (Table 4). The risk of an ACSC hospitalization for patients with at least four chronic diseases was 3.29 times higher than that of a patient without any chronic conditions. The number of body systems affected also increased the risk of an ACSC hospitalization, raising the risk by 1.55 for each additional body system (Table 5 ).

The body systems in which having chronic conditions had a greater impact on the risk of an ACSC hospitalization were: diseases of the respiratory system (8.72, $95 \%$ IC $p<0.001)$, diseases of the circulatory system (3.01, $95 \%$ IC $p<0.001)$, endocrine, nutritional and metabolic diseases, and immunity disorders (1.64, $95 \%$ IC $p<0.001$ ), and diseases of the nervous system and sense organs $(1.58,95 \%$ IC $p<0.001)$. If a patient had both a disease of the respiratory system and a disease of the circulatory system, the risk of an ACSC hospitalization was 26.19 times greater. Accumulating chronic conditions in all four body systems increased the risk of an ACSC hospitalization by 67.91 .

\section{Discussion}

The identification of hospitalizations for ambulatory care sensitive conditions does not commonly take into consideration multiple chronic conditions. However, in this study we determined that not only is the risk of an ACSC hospitalization higher for patients with multiple chronic conditions, but also that patients hospitalized

Table 4 Logistic regression for ACSC hospitalizations using the number of chronic conditions as the explanatory variable

\begin{tabular}{llll}
\hline Independent variable & Sig & Odds ratio & $95 \% \mathrm{Cl}$ \\
\hline $\begin{array}{l}\text { Number of chronic } \\
\text { conditions }\end{array}$ & $<0.001$ & 1.35 & $(1.34-1.35)$ \\
Age groups & & & \\
41 to 45 years & $<0.001$ & .34 & $(0.32-0.35)$ \\
46 to 50 years & $<0.001$ & .42 & $(0.41-0.43)$ \\
51 to 55 years & $<0.001$ & .47 & $(0.46-0.49)$ \\
56 to 60 years & $<0.001$ & .56 & $(0.54-0.57)$ \\
61 to 65 years & $<0.001$ & .60 & $(0.59-0.61)$ \\
66 to 70 years & $<0.001$ & .68 & $(0.67-0.70)$ \\
71 to 75 years & $<0.001$ & .80 & $(0.79-0.82)$ \\
Gender & $<0.001$ & 1.23 & $(1.21-1.24)$ \\
Predictive accuracy of & & & \\
the model: $95.4 \%$ & & & \\
Omnibus tests: $p<0.001$ & & & \\
Area under the curve: 0.762 & & & \\
\hline
\end{tabular}

Table 5 Logistic regression for ACSC hospitalizations using the number of body systems as the explanatory variable

\begin{tabular}{llll}
\hline Independent variable & Sig & Odds ratio & $95 \% \mathrm{Cl}$ \\
\hline Number of body systems & $<0.001$ & 1.55 & $(1.55-1.56)$ \\
Age groups & & & \\
41 to 45 years & $<0.001$ & .31 & $(0.30-0.33)$ \\
46 to 50 years & $<0.001$ & .39 & $(0.38-0.40)$ \\
51 to 55 years & $<0.001$ & .44 & $(0.43-0.45)$ \\
56 to 60 years & $<0.001$ & .52 & $(0.51-0.53)$ \\
61 to 65 years & $<0.001$ & .57 & $(0.56-0.59)$ \\
66 to 70 years & $<0.001$ & .66 & $(0.64-0.67)$ \\
71 to 75 years & $<0.001$ & .79 & $(0.78-0.81)$ \\
Gender & $<0.001$ & 1.27 & $(1.25-1.29)$
\end{tabular}

Predictive accuracy of the model: $95.5 \%$

Omnibus tests: $p<0.001$

Area under the curve: 0.735

for an ACSC have more chronic diseases and in more body systems than those hospitalized for a non-ACSC.

\section{Study population}

Our population characteristics were similar to the population in the literature reviewed. In the context of the present study, the most relevant results in literature are the increased prevalence of chronic conditions with age $[9,14]$ and the concentration of ACSC hospitalizations in the male and older population $[9,17]$. The most frequent ACSC found were heart failure and pulmonary edema, the same as reported by Sarmento [18].

The rate of ACSC hospitalizations in our sample was $4.5 \%$, which rose to $7.9 \%$ in the population over 65 years old, values similar to those obtained by Niti and Ng [19] and results obtained in Portugal $[17,20]$. The calculated rates are lower than other similar studies probably because of the higher percentage of elective hospitalizations in our study, which were nearly half of the population studied.

\section{Chronic conditions in the population}

Across all the hospitalizations in our sample we found that $76.3 \%$ had at least one chronic condition, $51.7 \%$ had at least two chronic conditions, and $20.3 \%$ had at least four chronic conditions. These results are similar to those described by Ajmera [11] and Wolff, Starfield, and Anderson [9].

Hospitalizations for diseases of the circulatory or respiratory systems are associated with a higher burden of chronic disease. For hospitalizations with a chronic condition in the circulatory or respiratory systems as the principal diagnosis, we found that $89.4 \%$ and $79.9 \%$ of the patients, respectively, had at least two chronic 
conditions and $51.6 \%$ and $41.8 \%$, respectively, had at least four chronic conditions.

When considering only ACSC hospitalizations, we found that the average number of both chronic conditions and body systems was higher than in non-ACSC hospitalizations. In fact, we observed an average of 3.93 chronic conditions in ACSC hospitalizations and only 1.98 chronic conditions in non-ACSC hospitalizations. When looking at body systems, we observed an average of 2.50 for ACSC hospitalizations and 1.49 for nonACSC hospitalizations. Ajmera and Wolff have reported similar findings $[9,11]$.

Impact of non-principal diagnoses in ACSC hospitalizations When studying the likelihood of being hospitalized for an ACSC, we found that the risk of such an event increases by a factor of 1.35 for each additional chronic condition and 1.55 for each additional body system.

Considering the body systems themselves, we found that having a chronic condition in the circulatory system or in the respiratory system increases the risk of an ACSC hospitalization by a factor of 8.72 and 3.01, respectively. There are similar results in the literature $[21,22]$, although earllier studies focused on patients with specific conditions. Balogh et al. [23], for example, identified a 2.6 times higher risk of hospitalization in patients with mental disorders.

The fact that the risk of an ACSC hospitalization increases with the number of chronic conditions can be explained by the patients' difficulty in managing the disease burden, particularly managing and adhering to various and complex therapeutic regimens [14]. This increased risk also suggests the challenges healthcare providers face with interdisciplinary and multidisciplinary care.

\section{Recommendations}

Using ACSC hospitalizations as a measure of access to care requires a good understanding of as many influencing factors as possible. Since the rates of hospitalization increase with both the number of chronic conditions and the number of body systems, these variables must be taken into account in the development of risk models for ACSC hospitalization indicators. Doing so will produce more meaningful findings when evaluating ACSC hospitalizations in the future, when performing countrywide or regional analyses.

Our findings indicate that chronic condition patterns are associated with varying risks of hospitalization. Therefore, individuals should be identified and targeted for specific prevention, treatment, and follow-up based on their chronic condition patterns, which represent different risks of hospitalization. Health policies should also consider strategies to stratify the population according to their chronic disease burden and risk of hospitalization, in order to plan appropriate care delivery and allocation of healthcare resources.

Interventions to reduce the rate of hospitalizations due to ACSC should also take this studies' findings in consideration, targeting patients at higher risk through better health promotion, using alternative clinical pathways, or enabling self-care. Integrated care should leverage technology to make more and better information available to clinicians -regarding both the patient's health status and condition-specific best practices thereby reducing the current number of ACSC hospitalizations.

\section{Study limitations}

From a methodology point of view, the quality of the data used is the main limitation. There are no known studies in Portugal that assure the accuracy or completeness of documented diagnoses. This is particularly important since the database is used for reimbursement purposes and data might not be documented in a way that is preferable for clinical studies. Most studies using the same database share this concern [24].

We could have used patients instead of hospitalizations as the unit of analysis. Doing so would provide more detail to characterize the secondary diagnosis but would reduce the burden of disease in the hospitalizations. Similar studies also consider hospitalizations instead of patients. Finally, the fact that we studied diagnoses in the context of an acute episode of care, and not longitudinally, did not allow us to explore a possible relationship of causality between morbidity and ACSC hospitalizations.

\section{Further research}

This study quantifies the effect of comorbidities in ACSC hospitalizations and the impact of multiple chronic conditions in these hospitalizations. This research would be enhanced by further exploring the onset and duration of chronic conditions, and probing potential causality between specific conditions and ACSC hospitalizations.

In addition, since it is clear that there are several variables influencing ACSC hospitalizations, it would be interesting to bundle the impact of chronic conditions with additional variables in order to build a model with increased power for predicting the risk of hospitalization due to ACSC.

\section{Conclusion}

This study adds to the knowledge on the impact of the secondary diagnosis in preventable hospitalizations. The risk of a preventable hospitalization increases by a factor of 1.35 for each additional chronic condition and 1.55 
for each additional body system. The body systems with the greatest impact in the risk of a preventable hospitalization are the respiratory and circulatory systems, the risk increasing by factors of 8.72 and 3.01, respectively.

These results point to the need to focus ambulatory setting interventions on patients with multiple chronic conditions, especially through continuous actions at a disease management level for the different chronic diseases, seeking to minimize the impact of chronic conditions in hospitalizations for ACSC.

Due to the increased prevalence of chronic conditions and high cost associated with treating chronic patients, further studying secondary diagnosis in preventable hospitalizations is critical to identify strategies that can minimize the impact of such hospitalizations on the Portuguese National Health System.

\section{Abbreviations}

ACSC, ambulatory care sensitive conditions; COPD, chronic obstructive pulmonary diseases; DRG, diagnosis related groups; HFPE, heart failure and pulmonary edema; HTN, hypertension

\section{Acknowledgements}

Not applicable.

\section{Funding}

Not applicable.

\section{Availability of data and materials}

The dataset supporting the conclusions of this article is available in the repository of the Portuguese Central Administration of the Health System. To preserve patients' privacy the raw data analyzed in this study cannot be shared, but can be made available upon request from the repository of the Portuguese Central Administration of the Health System.

\section{Authors' contributions}

All authors made a substantial contribution, revised critically and approved the final manuscript. ID carried out the data studies and drafted the manuscript. RS designed the study and coordinated the manuscript. JS defined ambulatory care sensitive conditions and chronic diseases. PA modeled the statistical analysis.

\section{Competing Interests}

The authors declare that they have no competing interests.

\section{Consent for publication}

Not applicable.

\section{Ethics approval and consent to participate}

Consent to participate is not applicable since anonymized patient-level data was used in the study. The utilization of the data for the present study was authorized.

The approval to use the data was obtained both from the Portuguese Central Administration of the Health System and the National School of Public Health

\section{Author details}

'National School of Public Health (ENSP), Universidade NOVA de Lisboa, Av. Padre Cruz, 1600-560 Lisbon, Portugal. '2Department of Health Policy and Systems Management, National School of Public Health (ENSP), Universidade NOVA de Lisboa, Av. Padre Cruz, 1600-560 Lisbon, Portugal. ${ }^{3}$ Public Health Research Centre (PHRC), National School of Public Health (ENSP), Universidade NOVA de Lisboa, Av. Padre Cruz, 1600-560 Lisbon, Portugal. ${ }^{4}$ Department of Strategies in Health, National School of Public Health (ENSP), Universidade NOVA de Lisboa, Av. Padre Cruz, 1600-560 Lisbon, Portugal.
Received: 19 January 2016 Accepted: 27 July 2016

Published online: 04 August 2016

\section{References}

1. Caminal J, Starfield B, Sánchez E, et al. The role of primary care in preventing ambulatory care sensitive conditions. Eur J Public Health. 2004;14(3):246-51

2. Agency for Healthcare Research and Quality. Prevention quality indicators [Internet]. Rockville: Agency for Healthcare Research and Quality; 2010 [cited 2016 Apr 08]. Available at: http://www.qualityindicators.ahrq.gov/ Downloads/Modules/PQI/N42/PQI Brochure_10 update.pdf

3. Walker R, Chen G, McAlister F, et al. Hospitalization for uncomplicated hypertension : an ambulatory care sensitive condition. Can J Cardiol. 2013;29(11):1462-9.

4. Ansari Z, Haider S, Ansari H, et al. Patient characteristics associated with hospitalisations for ambulatory care sensitive conditions in Victoria, Australia. BMC Health Serv Res. 2012;12(1):475.

5. Giuffrida A, Gravelle H, Roland M. Measuring quality of care with routine data : avoiding confusion between performance indicators and health outcomes. Br Med J. 1999:319(July):94-8.

6. Caminal J, Morales M, Sánchez E, et al. Hospitalizaciones prevenibles mediante una atención primaria oportuna y efectiva. Atención Primaria Elsevier. 2003;31(1):6-14

7. Portugal. Ministério da Saúde. DGS. Plano Nacional de Saúde 2012-2016 : 6. Indicadores e metas em saúde. Lisboa: Direcção-Geral da Saúde; 2012.

8. Anderson G. Chronic Care: Making the Case for Ongoing Care [Internet] Princeton: Robert Wood Johnson Foundation; 2010. [cited 2016 Apr 08], Available at: www.rwjf.org/pr/product.jsp?id=50968.

9. Wolff J, Starfield B, Anderson G. Prevalence, expenditures, and complications of multiple chronic conditions in the elderly. Arch Intern Med. 2002;162(20):2269-76.

10. Braunstein J, Anderson G, Gerstenblith G, et al. Noncardiac comorbidity increases preventable hospitalizations and mortality among medicare beneficiaries with chronic heart failure. J Am Coll Cardiol. 2003;42(7):1226-33.

11. Ajmera M, Wilkins T, Findley $P$, et al. Multimorbidity, mental illness, and quality of care : Preventable hospitalizations among medicare beneficiaries. Int J Family Med. 2012;2012(1):1-10.

12. Redelmeier D, Tan S, Booth G. The treatment of unrelated disorders in patients with chronic medical diseases. N Engl J Med. 1998;338(21):1516-20.

13. Balogh RS, Lake JK, Lin $\mathrm{E}$, et al. Disparities in diabetes prevalence and preventable hospitalizations in people with intellectual and developmental disability: a population-based study. Diabet Med. 2014;32(2):235-42.

14. Niefeld M, Braunstein J, Wu A, et al. Preventable hospitalization among elderly medicare beneficiaries with type 2 diabetes. Diabetes Care. 2003:26(5):1344-9.

15. Canadian Institute for Healthcare Information. Technical note : ambulatory care sensitive conditions (ACSC) [Internet]. Ottawa: Canadian Institute for Healthcare Information; 2008 [cited 2015 May 16]. Available at: http://www. cihi.ca/ClHI-ext-portal/internet/en/document/health+system+performance/ indicators/health/tech_acsc_2011

16. Agency for Healthcare Research and Quality. Chronic Condition Indicator [Internet]. Healthcare Cost and Utilization Project. Rockville: Agency for Healthcare Research and Quality; 2015 [cited 2015 May 30]. Available at: https://www.hcup-us.ahrq.gov/toolssoftware/chronic/chronic.jsp

17. Carneiro C. Essays on health economics: equity and access to health care and public hospital performance under corporatized management. Porto: Faculdade de Economia. Universidade do Porto; 2011.

18. Sarmento J, Alves C, Oliveira P, et al. Caracterização e evolução dos internamentos evitáveis em Portugal: Impacto de duas abordagens metodológicas. Acta Med Port. 2015;28(5):590-600.

19. Niti M, Ng T. Avoidable hospitalisation rates in Singapore, 1991-1998: assessing trends and inequities of quality in primary care. J Epidemio Community Heal. 2003;57(1):17-22

20. Portugal. Ministério da Saúde. Relatório anual sobre o acesso a cuidados de saúde nos estabelecimentos do SNS e entidades (2013). Lisbon: Ministério da Saúde; 2014. https://www.sns.gov.pt/wp-content/uploads/2016/07/201507-20-RA_Acesso_2014-VFinal.pdf

21. Bhattacharya R, Shen C, Sambamoorthi U. Depression and ambulatory care sensitive hospitalizations among Medicare beneficiaries with chronic physical conditions. Gen Hosp Psychiatry Elsevier. 2014:36(5): $460-5$. 
22. Davydow D, Zivin K, Katon W, et al. Neuropsychiatric disorders and potentially preventable hospitalizations in a prospective cohort study of older Americans. J Gen Intern Med. 2014;29(10):1362-71.

23. Balogh $\mathrm{R}$, Ouellette-Kuntz $\mathrm{H}$, Brownell $\mathrm{M}$, et al. Factors associated with hospitalisations for ambulatory care-sensitive conditions among persons with an intellectual disability: a publicly insured population perspective. J Intellect Disabil Res. 2013;57(3):226-39.

24. Caminal J, Sánchez E, Morales M, et al. Avances en España en la investigación con el indicador «hospitalización por enfermedades sensibles a cuidados de atención primaria». Rev Esp Salud Publica. 2002;76(3):189-96.

Submit your next manuscript to BioMed Central and we will help you at every step:

- We accept pre-submission inquiries

- Our selector tool helps you to find the most relevant journal

- We provide round the clock customer support

- Convenient online submission

- Thorough peer review

- Inclusion in PubMed and all major indexing services

- Maximum visibility for your research

Submit your manuscript at www.biomedcentral.com/submit
Biomed Central 